\title{
Impedance spectroscopy of bismuth sodium titanate: Barium titanate ceramics with manganese doping
}

\section{Authors: V. Hugo Schmidt, Noah Archer, and Chi- Shun Tu}

This is the peer reviewed version of the following article: see citation below, which has been published in Journal of the American Ceramic Society and can be found in final form at https:// dx.doi.org/10.1111/jace.15236. This article may be used for non-commercial purposes in accordance with Wiley Terms and Conditions for Self-Archiving.

Schmidt, V. Hugo, Noah Archer, and Chi-Shun Tu. "Impedance spectroscopy of bismuth sodium titanate: Barium titanate ceramics with manganese doping." Journal of the American Ceramic Society 101, no. 2 (February 2018): 713-722. DOI: 10.1111/jace.15236.

Made available through Montana State University's $\underline{\text { ScholarWorks }}$ scholarworks.montana.edu 


\title{
Impedance spectroscopy of bismuth sodium titanate: Barium titanate ceramics with manganese doping
}

\author{
V. Hugo Schmidt ${ }^{1}$ | Noah Archer ${ }^{1}$ | Chi-Shun $\mathbf{T u}^{2}$ \\ ${ }^{1}$ Department of Physics, Montana State \\ University, Bozeman, Montana \\ ${ }^{2}$ Department of Physics, Fu Jen Catholic \\ University, New Taipei City, Taiwan
}

\begin{abstract}
In this work we use Impedance Spectroscopy (IS) to study lead-free ceramics of perovskite structure $\left(\mathrm{Bi}_{1 / 2} \mathrm{Na}_{1 / 2} \mathrm{TiO}_{3}\right)_{0.925}\left(\mathrm{BaTiO}_{3}\right)_{0.075}$ with Mn doping of $0,0.2$, 1.0, and 2.0 at.\%. We compare our IS results with permittivity results, using dielectric to resistivity transformation equations which allow us to display results either as permittivity or as resistivity. We observe ionic conductivity dominating at lower temperatures, giving way to electronic conductivity at higher temperatures. The permittivity shows deviations from Curie-Weiss behavior characteristic of relaxor ferroelectrics. The $0.2 \% \mathrm{Mn}$ samples show the highest ionic resistivity, which will reduce heating for high voltage piezoelectric applications. They also have the highest Curie-Weiss temperature and Burns temperature.
\end{abstract}

\section{1 | INTRODUCTION}

Ceramics based on grains of piezoelectric perovskite crystals have good piezoelectric response in the vicinity of the morphotropic phase boundary (MPB), but many of them contain lead which is toxic. Bismuth sodium titanate $\left(\mathrm{Bi}_{1 / 2} \mathrm{Na}_{1 / 2}\right) \mathrm{TiO}_{3}$ (BNT) based materials attract attention because of their large piezoelectric responses, which are comparable to those of lead-containing $\mathrm{Pb}(\mathrm{Zr}, \mathrm{Ti}) \mathrm{O}_{3}$ (PZT) solid solutions. ${ }^{1-14}$ Most studies of BNT-based compounds include $\mathrm{BNT}^{-\mathrm{BaTiO}_{3}},{ }^{2-5}$ BNT- $\left(\mathrm{Bi}_{1 / 2} \mathrm{~K}_{1 / 2}\right) \mathrm{TiO}_{3},{ }^{6}$ BNT$\mathrm{KNbO}_{3},{ }^{7}$ BNT-BiFeO $3{ }_{3},{ }^{8}$ BNT-SrTiO ${ }_{3},{ }^{9}$ BNT- $\left(\mathrm{Bi}_{1 / 2} \mathrm{~K}_{1 / 2}\right)$ $\mathrm{TiO}_{3}-\mathrm{SrTiO}_{3},{ }^{10} \mathrm{BNT}-\mathrm{BaTiO}_{3}-\left(\mathrm{K}_{0.5} \mathrm{Na}_{0.5}\right) \mathrm{NbO}_{3},{ }^{11} \mathrm{Zr}$-doped BNT- $\mathrm{BaTiO}_{3},{ }^{12}$ and Mn-doped BNT-BaTiO ${ }_{3}{ }^{13,14}$ Among the BNT-based materials, bismuth sodium titanate-barium titanate $(1-y)\left(\mathrm{Bi}_{1 / 2} \mathrm{Na}_{1 / 2}\right) \mathrm{TiO}_{3}-y \mathrm{BaTiO}_{3}$ solid solutions near the morphotropic phase boundary (MPB) $(y=0.06$ 0.08 ) between rhombohedral and tetragonal structures are of particular interest due to enhanced piezoelectric responses, ${ }^{15-17}$ accompanied by polar nanoregions (PNRs) and large electric $(E)$-field-induced piezoelectricity. ${ }^{17-19}$ However, as mentioned in a recent review, the lower depolarization temperature $T_{\mathrm{d}}$ for compositions near the MPB causes concern regarding thermal stability under long-time operation. $^{20}$

We made two previous studies ${ }^{14,21}$ of $\left(\mathrm{Bi}_{1 / 2} \mathrm{Na}_{1 / 2}\right)_{0.925}$ $\mathrm{Ba}_{0.075}\left(\mathrm{Ti}_{1 \mathrm{x}} \mathrm{Mn}_{x}\right) \mathrm{O}_{3}$ for $x=0,0.2, \quad 1.0$, and $2.0 \mathrm{~mol} \%$ (BNT7.5BT: $x \% \mathrm{Mn}$ ) ceramics, which are exactly the same four compositions examined in the present work. We found that manganese doping suppressed dielectric permittivity and increased relaxor behavior. ${ }^{21}$ Coercive field $\left(E_{\mathrm{c}}\right)$ increases while remanent polarization $\left(P_{\mathrm{r}}\right)$ decreases as $\mathrm{Mn}$ content increases. Most importantly, the depolarization temperature $\left(T_{\mathrm{d}}\right)$ was enhanced remarkably to $\sim 152^{\circ} \mathrm{C}$ for the $0.2 \% \mathrm{Mn}$ composition, compared to $93^{\circ} \mathrm{C}$ for no $\mathrm{Mn}$. This enhanced $T_{\mathrm{d}}$ was attributed to two-phase coexistence and structural thermal stability induced by Mn ions. High-resolution synchrotron XRD and transmission electron microscopy (TEM) revealed two-phase coexistence of rhombohedral and tetragonal structures for $x=0$ and $0.2 \%$ $\mathrm{Mn}$ and an orthorhombic phase in 1 and $2 \%$ Mn-doped BNT7.5BT at room temperature. ${ }^{14}$ Scanning electron microscopy (SEM) showed grain sizes increasing from $2.1 \mu \mathrm{m}$ for $0 \% \mathrm{Mn}$ to $5.2 \mu \mathrm{m}$ for $2.0 \% \mathrm{Mn}^{14}$ Insitu temperaturedependent Raman spectra of $0 \%$ Mn BNT7.5BT revealed a structural transition from two-phase coexistence to 
tetragonal phase near $190^{\circ} \mathrm{C}$ with a phonon softening anomaly. ${ }^{14}$ Also, $0.2 \%-2 \%$ Mn-doped BNT7.5BT showed phonon softening near $290^{\circ} \mathrm{C}$ upon heating. ${ }^{14} \mathrm{We}$ concluded that $\mathrm{Mn}$ doping can enhance structural thermal stability in $\mathrm{BN7.5BT}$ ceramics as temperature increases.

This paper continues in Section 2 with experimental procedure including sample characterization. The presentation and discussion of experimental results in Section 3 begins in Section 3.1 with using ac impedance spectroscopy results to determine ac permittivity behavior. To make this determination we use the conversion relations between impedance and permittivity derived and presented in the Appendix A These permittivity results in Section 3.1, show intertwined dielectric and conductivity behavior, including effects of phase-shifted conductivity. ${ }^{22}$ The dielectric behavior is typical of relaxor ferroelectrics, ${ }^{2}$ obeying a power law relation above the dielectric peak and then the Curie-Weiss law above the Burns temperature. The ac conductivity behavior is presented in Section 3.2, as Cole-Cole arcs of imaginary vs real resistivity. The plot for each temperature is adjusted by a "collapse" factor to factor out the exponential temperature dependence and allow easy comparison of plots for different temperatures. In Section 3.3, the dc resistivity is presented in semilogarithmic plots vs inverse temperature, which show both ionic and electronic contributions to the conductivity. These results and their implications are summarized in Section 4.

\section{2 | EXPERIMENTAL PROCEDURE}

The $\left(\mathrm{Bi}_{1 / 2} \mathrm{Na}_{1 / 2} \mathrm{TiO}_{3}\right)_{0.925} \mathrm{Ba}_{0.075}\left(\mathrm{Ti}_{1-x} \mathrm{Mn}_{x}\right) \mathrm{O}_{3}$ ceramic disks of about $1 \mathrm{~mm}$ thickness and $8.3 \mathrm{~mm}$ diameter were fabricated without and with B-site $\mathrm{Mn}$ doping, designated BNT7.5BT and BNT7.5BT:x\%Mn', respectively. As indicated in this formula, it is expected that all Mn ions go into perovskite "B" sites, otherwise occupied by $\mathrm{Ti}$ ions, because of ionic size and valence considerations. These ceramics were prepared using the solid-state reaction. The starting materials were high purity $(>99 \%)$ powders of $\mathrm{Bi}_{2} \mathrm{O}_{3}, \mathrm{Na}_{2} \mathrm{CO}_{3}, \mathrm{BaCO}_{3}, \mathrm{TiO}_{2}$, and $\mathrm{MnO}_{2}$. Stoichiometric amounts of powders were ball-milled for more than 24 hours in ethanol. The mixture was calcined at $900^{\circ} \mathrm{C}$ for 2 hour and a Retsch PM100 planetary ball mill was used to reduce particle size. The calcined powders were then pressed into disks that were sintered for 2 hours at $1170^{\circ} \mathrm{C}$.

Three disks each were prepared with $x=0,0.2,1.0$, and 2.0 at.\% Mn doping. These are exactly the same $x$ values as prepared in different ceramic batches in two of our previous works. ${ }^{14,21}$ The compositions are also close to those reported by Zhu et al, ${ }^{23}$ who used $8.0 \%$ instead of $7.5 \% \mathrm{Ba}$ and atomic\% $\mathrm{Mn} x$ values of $0,0.45,0.9,1.5$, 2.25, and 3.0. (They reported $\mathrm{wt} \% \mathrm{MnO}$ values of $0,0.15$,
$0.3,0.5,0.75$, and 1.0 , and the conversion factor for wt $\%$ to at.\% is almost exactly 1 to 3 .). Their average density was $5.62 \mathrm{~g} / \mathrm{cm}^{3}$. Our densities found by the Archimedes method for samples with $0,0.2,1.0$, and $2.0 \% \mathrm{Mn}$ are $5.12,4.98,5.67$, and $5.74 \mathrm{~g} / \mathrm{cm}^{3}$, respectively. The average density reported in Ref. [14] using the Archimedes method for $x=0,0.2,1.0$, and $2.0 \% \mathrm{Mn}$ was $5.79 \mathrm{~g} / \mathrm{cm}^{3}$. The theoretical full density based on unit cell dimensions from XRD and on the unit cell molecular weight is $5.78 \mathrm{~g} / \mathrm{cm}^{3}$.

Shown and discussed in the Data S1 are field-emission Scanning Emission Microscopy (SEM) micrographs and XRay Powder Diffraction spectrometer (XRD) patterns for disks with each Mn concentration.

Overall, our sample characterization by density, FEM, and XRD measurements show that our samples are pure and of the expected perovskite structure. Differences between our measurements and those from Ref. [14] and from $\mathrm{Zhu}^{23}$ can be attributed to these compositions being near the morphotropic phase boundary, where small intended or unintended composition and processing differences can have large effects. In particular, it seems from our XRD results compared with those of Ref. [14], that our samples are closer to the parent cubic perovskite structure than those of Ref. [14], for which indications of rhombohedral, tetragonal, and orthorhombic phases were reported.

Disks were prepared for impedance spectroscopy (IS) by coating both faces with Ted Pella Inc. No. 16032 colloidal silver paste. The disks were not polarized. Fine 30 -gauge silver wires were attached by dabs of silver paste to each face, and to the terminals inside a small $10-\mathrm{cm}$ diameter homebuilt water-cooled oven which can attain $1000^{\circ} \mathrm{C}$. These terminals were connected to a Solartron SI 1260 Impedance Gain-Phase Analyzer. Temperature was maintained and monitored with a Eurotherm 2404 controller. Runs were made from $100^{\circ} \mathrm{C}$ to $500^{\circ} \mathrm{C}$ or $600^{\circ} \mathrm{C}$ in $50^{\circ} \mathrm{C}$ steps using a $3^{\circ} \mathrm{C} /$ minute ramp rate, and a hold time of 5 minutes before measurements at each temperature. The frequencies used in earlier runs were $1 \mathrm{~Hz}$ to $1 \mathrm{MHz}$ in 61 logarithmically spaced steps, and changed to start at $0.1 \mathrm{~Hz}$ and use 71 steps in later runs. For the earlier runs we thought that $1 \mathrm{~Hz}$ would be sufficient as a lowest frequency, but after analyzing these data we decided that $0.1 \mathrm{~Hz}$ for the later runs would be worth the considerable extra experimental time. Four runs through the frequency range were made at each temperature to verify that impedance did not change with time.

\section{3 | RESULTS AND DISCUSSION}

\section{1 | Permittivity calculated from transformed resistivity}

Using the data for $1 \mathrm{~Hz}, 1 \mathrm{kHz}$, and $1 \mathrm{MHz}$ for the most recent runs, for which our maximum temperature was 
$600^{\circ} \mathrm{C}$ instead of $500^{\circ} \mathrm{C}$, we use Equations $\mathrm{A} 9$ and $\mathrm{A} 10$ in the Appendix A to plot $\varepsilon^{\prime}$ and $\tan \delta$ vs $T$. These plots appear in Figure 1 for Mn concentrations of 0, 0.2\%, 1.0\%, and $2.0 \%$, respectively. The higher temperature points for the $1 \mathrm{MHz}$ runs were fit to the Curie-Weiss law as shown by dashed lines. Four of the points for $1 \mathrm{~Hz}$ are off scale because of high conductivity (for $\tan \delta$ ) and the phaseshifted component of this high conductivity (for $\varepsilon^{\prime}$ ). Specifically, the calculated point for $\varepsilon^{\prime}$ for $0 \% \mathrm{Mn}$ for $1 \mathrm{~Hz}$ is not shown because it is off scale (above 9000). Also, the calculated points for $\tan \delta$ for $1 \mathrm{~Hz}$ are not shown for $0 \%, 1.0 \%$, and $2.0 \% \mathrm{Mn}$ because they are off scale (above 0.45 ). The vertical scale is not extended higher because such extension would not provide additional useful permittivity information. It would only provide indirectly some conductivity information, paralleling the conductivity information provided elsewhere in this paper. Specifically, the reason for not extending the vertical scale higher is best understood by looking at the Figure for $0.2 \% \mathrm{Mn}$ which does show the $1 \mathrm{~Hz}$ points for both $\varepsilon^{\prime}$ and $\tan \delta$. Both of these red curves are increasing with temperature almost exponentially at their highest temperatures, where their temperature dependences are governed almost entirely by phase shifted conductivity and by conductivity, respectively, as discussed elsewhere. Extending the vertical scale upward on all four Figure sections would only provide more of such exponential upturns.

The results for the four Mn concentrations show general agreement for both the relaxor ferroelectric permittivity including dielectric loss, and for the conductivity including phase-shifted conductivity. In discussing permittivity and conductivity phenomena, we define permittivity as any response that does not involve carriers moving from one unit cell to another, and conductivity as the response of ions or electrons that do drift from cell to cell under an electric field. One might think that conductivity behavior should appear only in $\tan \delta$, but because of phase-shifted conductivity ${ }^{22}$ it appears also in $\varepsilon^{\prime}$. Every point, whether for $\varepsilon^{\prime}$ or for $\tan \delta$, that would appear above the top of the plot, disappears because of the conductivity which increases exponentially with temperature. The upturn in $\tan \delta$ at high temperature for
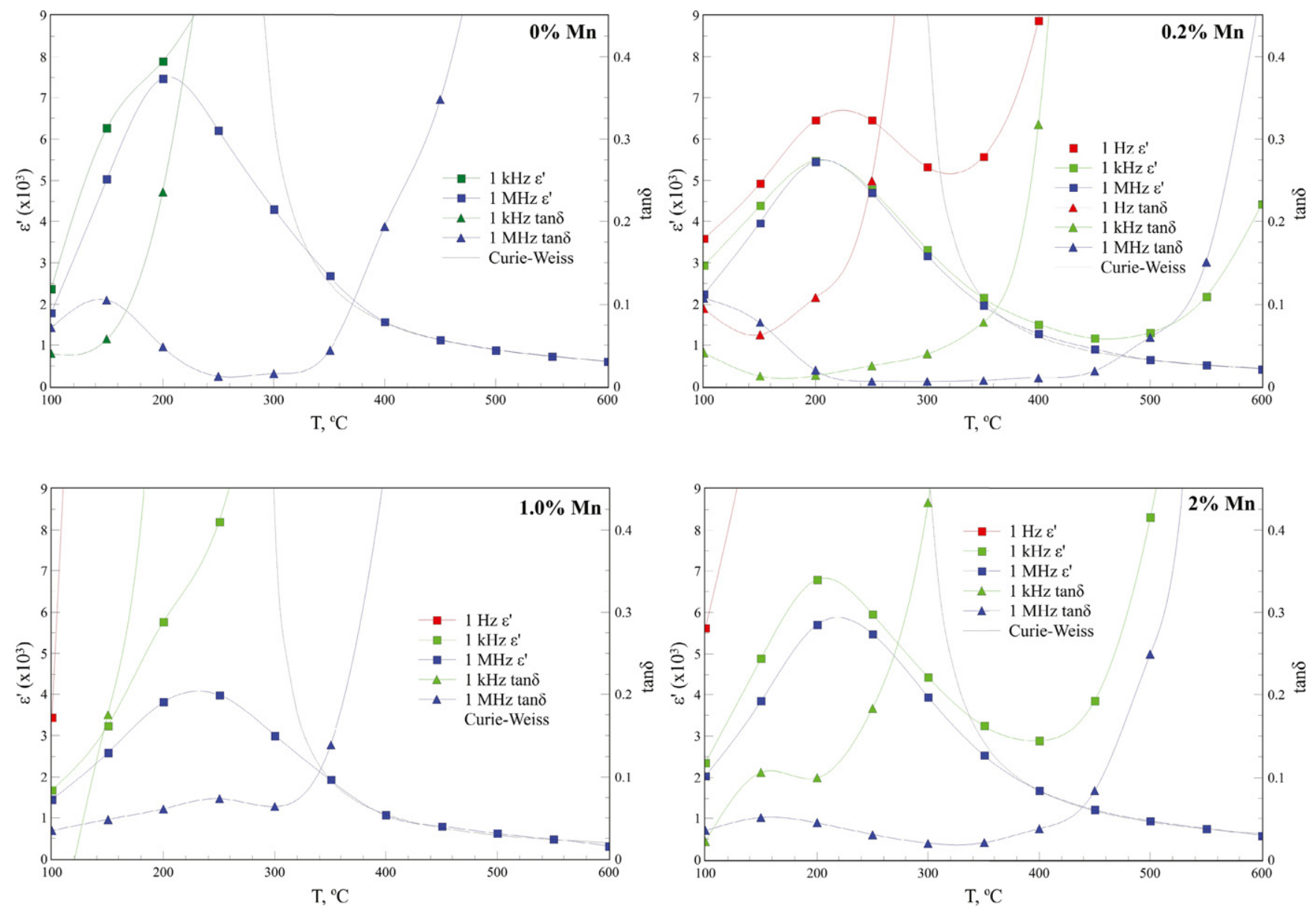

FIGURE 1 Permittivity and tan $\delta$ vs temperature for samples with $0 \%, 0.2 \%, 1.0 \%$, and $2.0 \% \mathrm{Mn}$. The symbols at $50^{\circ}$ temperature intervals indicate values of $\varepsilon^{\prime}$ and $\tan \delta$ calculated from our impedance data using Equations A9 and A10, respectively, in the Appendix A. The lines are guides for the eye. Some calculated points are off-scale because of high conductivity, as discussed in the text. Fits to the Curie-Weiss law in Equation 1 are shown [Color figure can be viewed at wileyonlinelibrary.com] 
the $0.2 \% \mathrm{Mn}$ sample at $1 \mathrm{kHz}$ is also due to conductivity; otherwise it would follow the $1 \mathrm{MHz}$ curve. Our samples show the typical relaxor ferroelectric behavior of a rounded peak rather than the sharp $\varepsilon^{\prime}$ peak characteristic of ordinary ferroelectrics. The peaks appear at temperatures $T_{\mathrm{m}}$ of $206^{\circ} \mathrm{C}$ to $230^{\circ} \mathrm{C}$, and vary somewhat in height. The dielectric (not conductive) anomalies in $\tan \delta$ associated with these $\varepsilon^{\prime}$ peaks show up as small rounded peaks in $\tan \delta$ on the low-temperature side.

We compare results in Table 1 for four Mn concentrations in Figure 1 with those shown in Figure 1 of Ref. [21], for samples with the same Mn concentrations prepared in the same laboratory of co-author C.-S. Tu but from different batches. These comparisons are made at $1 \mathrm{MHz}$, because at lower frequencies some $\varepsilon^{\prime}$ peaks are shifted upward or even off scale by the phase-shifted conductivity effect. The results for both sample sets are qualitatively similar. Specifically, the peak permittivities for both sample sets lie between 4090 and 7500 , and the temperatures $T_{\mathrm{m}}$ at these peaks lie between $206^{\circ} \mathrm{C}$ and $250^{\circ} \mathrm{C}$. This strong overlap gives confidence that the temperature, permittivity, and resistivity calibrations in both laboratories are consistent.

To compare $\varepsilon^{\prime}$ permittivity for different samples, it is useful to have expressions with parameters which can be fit to the data. Below the temperature $T_{\mathrm{m}}$ for peak permittivity $\varepsilon_{\mathrm{m}}$, the fit may be difficult because there may be phase transitions in this region, as seen in figure 9 of Ref. [21], so we attempt to fit the data only above $T_{\mathrm{m}}$. Above $T_{\mathrm{m}}$, relaxor ferroelectric behavior caused by dipole clustering can be fit by a power relation up to the Burns temperature $T_{\mathrm{B}}$. Above $T_{\mathrm{B}}$, dipole clustering ceases and the sample obeys the Curie-Weiss law as for an ordinary ferroelectric. The $T_{\mathrm{B}}$ values range from $343^{\circ} \mathrm{C}$ to $443^{\circ} \mathrm{C}$ as shown in Table 1 .

As usual, the fit to the Curie-Weiss law

$$
\varepsilon^{\prime}(T, f)=C /\left(T-T_{0}\right) ; 1 / \varepsilon^{\prime}=\left(T-T_{0}\right) / C
$$

is performed by plotting $1 / \varepsilon^{\prime}$ vs $\mathrm{T}$. The higher-temperature points fit a straight line well. The temperature at which the extrapolated line hits the $1 / \varepsilon^{\prime}=0$ axis is the Curie-Weiss temperature $T_{0}$. The inverse of the slope of the line is the Curie-Weiss constant C. Because $\varepsilon^{\prime}$ can exhibit an upturn at high temperatures and low frequencies due to phaseshifted conductivity, ${ }^{22}$ we evaluate $T_{0}$ and $C$ at our highest $f$ value, $1 \mathrm{MHz}$. Table 1 presents values for $T_{0}$ and $C$, including values from Ref. [2].

Turning to the power-law region for which dipole clustering is prevalent, we are still at temperatures above the usual piezoelectric application range. For this region, Table 1 presents the experimental parameters $T_{\mathrm{m}}$ and the power-law-fit parameters $\gamma$ and $\Delta$. The power relation, which is applicable between $T_{\mathrm{m}}$ and $T_{\mathrm{B}}$, is written as

$$
1 / \varepsilon^{\prime}=\left(1 / \varepsilon_{\mathrm{m}}^{\prime}\right)\left\{1+\frac{1}{2}\left[\left(T-T_{\mathrm{m}}\right) / \Delta\right]^{\gamma}\right\}
$$

This relation was apparently first proposed by Martirena and Burfoot. ${ }^{24}$ They stated that the value 2 for the power $\gamma$ corresponds to behavior for a "diffuse ferroelectric transition" which now is called relaxor ferroelectric behavior, whereas the value 1 corresponds to Curie-Weiss behavior. An expression similar to Equation 2 appears in Ref. [21], except that only $\left(T-T_{\mathrm{m}}\right)$ is taken to the power $\gamma$, while $1 / \Delta^{\gamma}$ is replaced by $1 / \Delta^{2}$. In that Ref. [21] expression, $\Delta$ which they call the broadening constant has dimensions of temperature only if $\gamma=2$.

The method ${ }^{21}$ for determining the power $\gamma$ starts by rewriting Equation 2 in terms of natural logarithms using the following steps, in which only $\varepsilon^{\prime}$ is a function of $T$ :

$$
\varepsilon_{\mathrm{m}}^{\prime} / \varepsilon^{\prime}=1+\left(\varepsilon_{\mathrm{m}}^{\prime}-\varepsilon^{\prime}\right) / \varepsilon^{\prime}=1+\frac{1}{2}\left[\left(T-T_{\mathrm{m}}\right) / \Delta\right]^{\gamma} .
$$

Subtracting 1 from each side and taking the $\ln$, we obtain

$$
\ln \left[\left(\varepsilon_{\mathrm{m}}^{\prime}-\varepsilon^{\prime}\right) / \varepsilon^{\prime}\right]=\gamma \ln \left(T-T_{\mathrm{m}}\right)-\ln 2-\gamma \ln \Delta .
$$

Next, we plot $\left.\ln \left[\left(\varepsilon_{\mathrm{m}}^{\prime}-\varepsilon^{\prime}\right) / \varepsilon^{\prime}\right)\right] v s \cdot \ln \left(T-T_{\mathrm{m}}\right)$ over the range $T_{\mathrm{m}}<T<T_{\mathrm{B}}$, using equal horizontal and vertical

\begin{tabular}{|c|c|c|c|c|c|c|c|c|}
\hline Sample, \% Mn & $T_{\mathrm{B}}^{\circ}{ }^{\circ} \mathrm{C}$ & $T_{0},{ }^{\circ} \mathrm{C}$ & $C, 10^{5 \circ} \mathrm{C}$ & $T_{\mathrm{m}},{ }^{\circ} \mathrm{C}$ & & $\gamma$ & $\Delta,{ }^{\circ} \mathbf{C}$ & References \\
\hline \multirow[t]{2}{*}{0} & 417 & 307 & 3.28 & & & 1.81 & 83 & Ref. [2] \\
\hline & 417 & & & 272 & & 1.81 & 83 & Ref. [21] \\
\hline \multirow[t]{2}{*}{0.2} & 420 & & & 243 & & 1.93 & 80 & Ref. [21] \\
\hline & 443 & $316 \pm 3$ & $1.22 \pm 0.02$ & 208 & 5500 & $1.97 \pm 0.03$ & $75 \pm 2$ & This work \\
\hline 1.0 & 348 & $280 \pm 6$ & $1.32 \pm 0.05$ & 230 & 4090 & $2.12 \pm 0.05$ & $85 \pm 2$ & This work \\
\hline \multirow[t]{2}{*}{2.0} & 429 & & & 215 & & 1.96 & 89 & Ref. [21] \\
\hline & 413 & $280 \pm 4$ & $2.06 \pm 0.04$ & 220 & 5900 & $1.96 \pm 0.07$ & $80 \pm 3$ & This work \\
\hline
\end{tabular}
scales, as shown in Figure 2. We fit the data points for each temperature to a straight line whose slope is $\gamma$. The

TA B LE 1 Curie-Weiss and power law fit parameters and peak permittivities for various Mn concentrations 


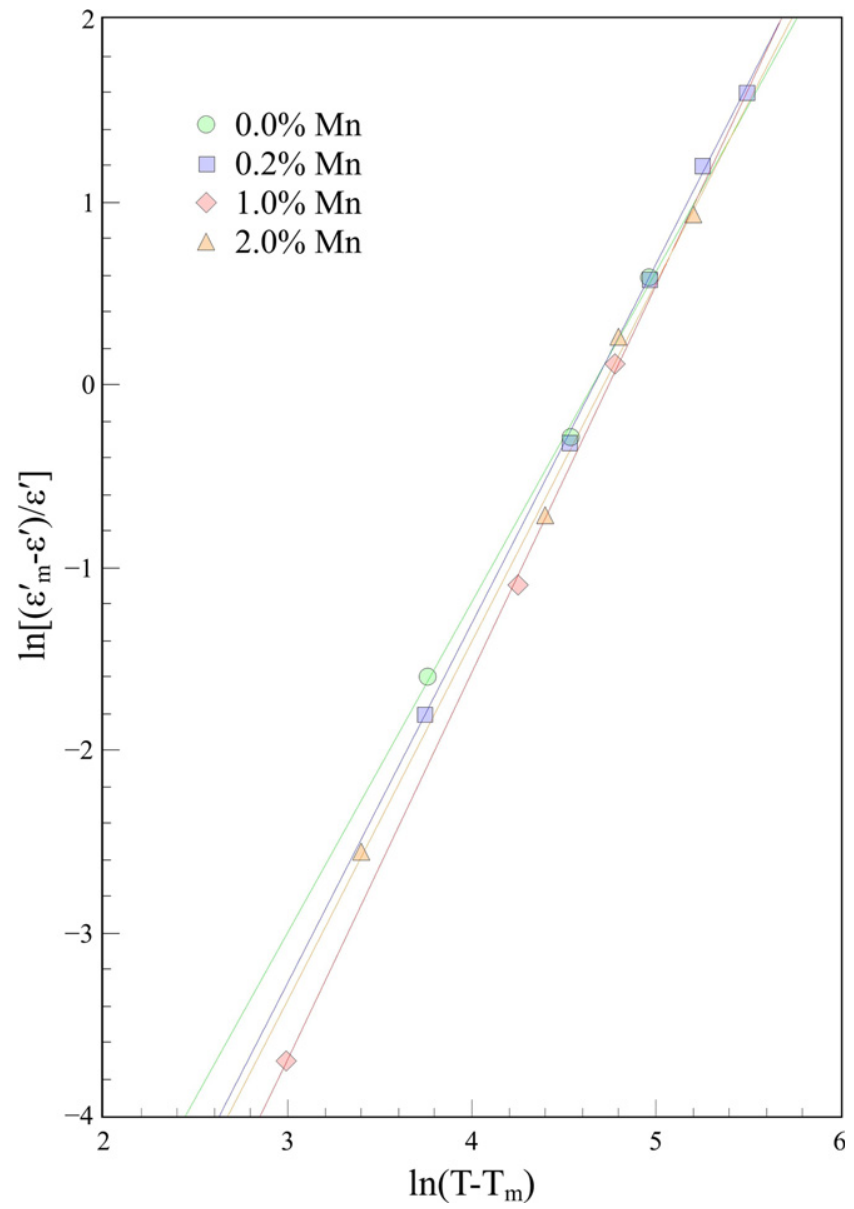

FIGURE 2 Logarithmic plot used in finding the power law exponent $\gamma$ and the width parameter $\Delta$ for the permittivity in the temperature region between the maximum permittivity temperature $T_{\mathrm{m}}$ and the Burns temperature $T_{\mathrm{B}}$ [Color figure can be viewed at wileyonlinelibrary.com]

broadening constant $\Delta$ is found by rearranging Equation 4 as $\quad \Delta=\left(T_{\mathrm{B}}-T_{\mathrm{m}}\right) /\left[2\left(\varepsilon_{\mathrm{m}}-\varepsilon_{\mathrm{B}}\right) / \varepsilon_{\mathrm{B}}\right]^{1 / \gamma}$,

where $\varepsilon_{B}$ is the permittivity found from the Curie-Weiss fit line at $T_{\mathrm{B}}$. This formula for $\Delta$ allows no magnitude discontinuity between the power law and Curie-Weiss fit lines at $T_{\mathrm{B}}$. There will, however, be a slope discontinuity. Such a discontinuity can be expected because Equation 2 is merely an empirical fit not derived from basic physics. Its value is in providing the constants $\gamma$ and $\Delta$ describing the relaxor behavior. Table 1 presents values from our work and Ref. [21] for $\gamma$ and $\Delta$. The agreement between the Ref. [21] results and ours for $\gamma$ and $\Delta$ is quite satisfying. Their exponent $\gamma$ increases with Mn content monotonically toward 2 , agreeing with our values almost exactly except for the $1 \%$ Mn sample, where we found $\gamma=2.12$. Note that $\gamma>2$ is theoretically possible; it just means that the permittivity at higher temperatures drops off faster than predicted by the power law with $\gamma=2$. The width parameter $\Delta$ values from both labs agree well, showing an upward trend with increasing Mn content. These upward trends for both $\gamma$ and $\Delta$ indicate increasing relaxor behavior. ${ }^{21}$

\section{2 | Impedance spectroscopy}

Using ac impedance spectroscopy (IS), ${ }^{25}$ we obtained impedance plots of $-\rho^{\prime \prime}$ vs $\rho^{\prime}$ for four Mn concentrations from $100^{\circ} \mathrm{C}$ to $600^{\circ} \mathrm{C}$. A plot of $-\rho^{\prime \prime}$ vs $\rho^{\prime}$ for a $1 \% \mathrm{Mn}$ sample at $250^{\circ} \mathrm{C}$ appears in Figure 3. It is untypical in that it shows two arcs more prominently than any of the other plots. In Figure 4 we present four plots, one for each $\mathrm{Mn}$ concentration, with the data "collapsed" or "scaled" to factor out the large thermally activated temperature dependence of the impedance. We used a similar presentation method previously ${ }^{26}$ for $\mathrm{Bi}_{1 x} \mathrm{Nd}_{x} \mathrm{FeO}_{3}$ multiferroic ceramics. To collapse the data for a given sample for different temperatures, instead of plotting $-\rho^{\prime \prime}$ vs $\rho^{\prime}$, we plot $-\rho^{\prime \prime} e^{x}$ vs $\rho^{\prime} e^{x}$, where

$$
e^{x} \equiv \exp \left[\left(E_{\mathrm{a}} / k_{\mathrm{B}}\right)(1 / 673-1 / T)\right] .
$$

Here, $E_{\mathrm{a}}$ is the activation energy in joules, $k_{\mathrm{B}}$ is Boltzmann's constant, 673 is the Kelvin temperature corresponding to $400^{\circ} \mathrm{C}$, and $T$ is the Kelvin temperature for a

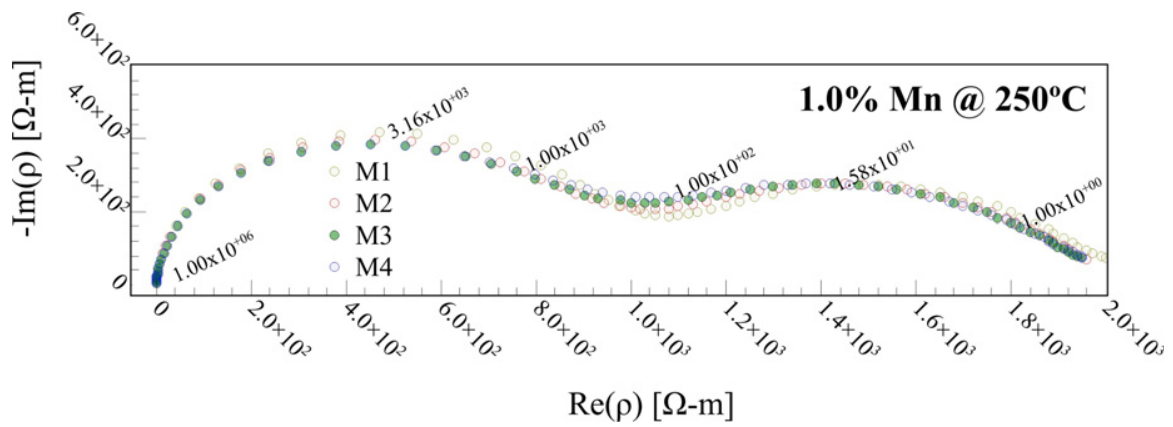

F IG URE 3 Plot of raw resistivity data showing negative imaginary resistivity vs real resistivity for a $1 \% \mathrm{Mn}$ sample at $250^{\circ} \mathrm{C}$. The four different color circles are four consecutive runs at fixed $250^{\circ} \mathrm{C}$. The circles are data points for frequencies ranging from $0.1 \mathrm{~Hz}$ to $1 \mathrm{MHz}$ with ten logarithmically spaced frequencies per decade. This plot is atypical in that it shows the strongest second (right-hand) arc [Color figure can be viewed at wileyonlinelibrary.com] 

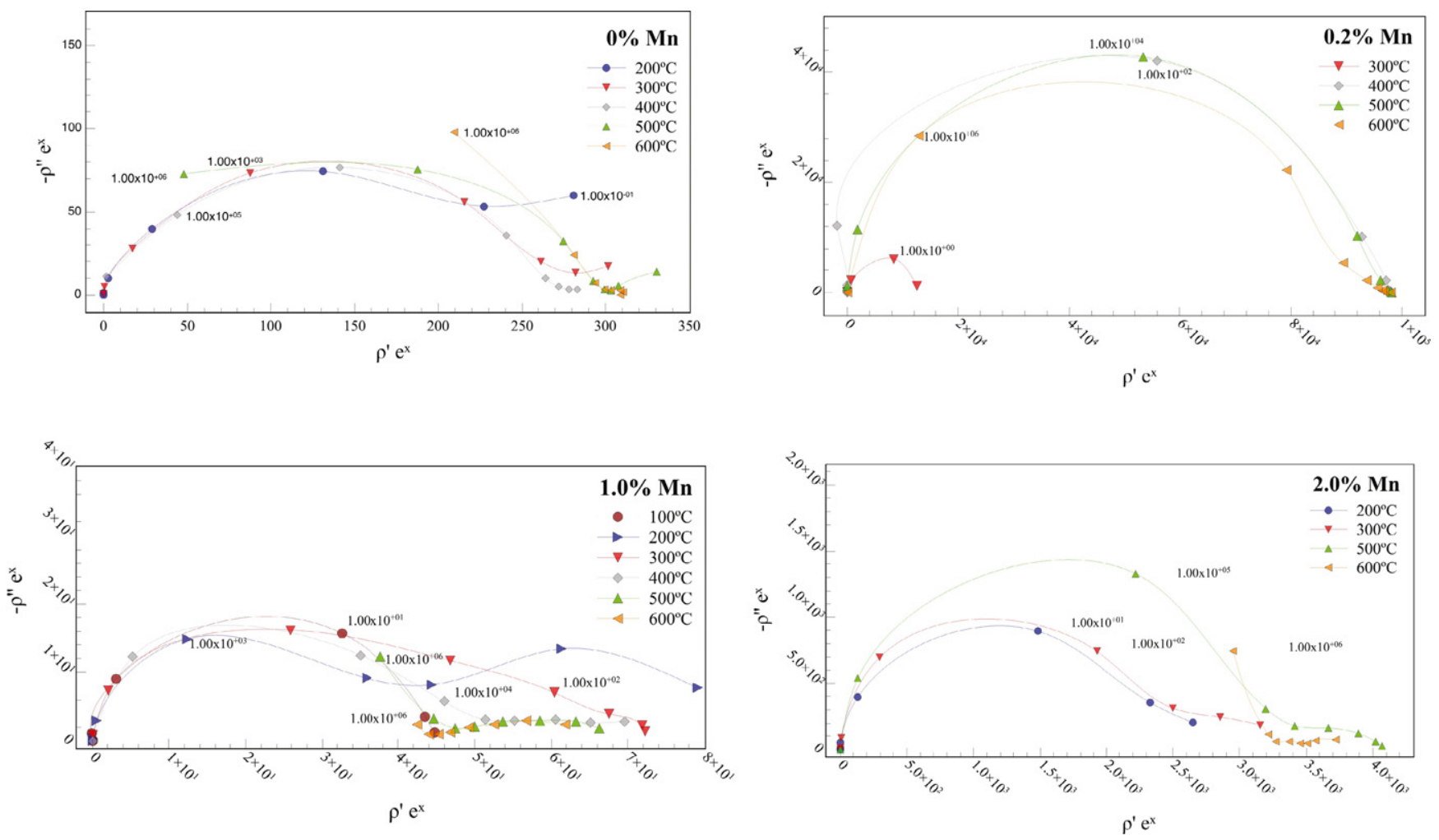

F I G URE 4 "Collapsed" resistivity plots for samples with $0 \%, 0.2 \%, 1.0 \%$, and $2.0 \% \mathrm{Mn}$. The collapse factor is $e^{x} \equiv \exp \left[\left(E_{\mathrm{a}} / k_{\mathrm{B}}\right)(1 / 673-1 /\right.$ $T)$ ] as discussed in the text associated with Equation 6 . Because $673 \mathrm{~K}$ is the Kelvin temperature associated with the $400^{\circ} \mathrm{C}$ runs, the $400^{\circ} \mathrm{C}$ resistivities correspond to the numbers on the horizontal and vertical scales because $e^{x}=1$. The $E_{\mathrm{a}}$ activation energies appear in Table 2 and must be multiplied by $1.602 \times 10^{-19} \mathrm{~J} / \mathrm{eV}$ for use in the $e^{x}$ formula. The symbols are shown only for frequencies at each decade, $10^{-1}-10^{6} \mathrm{~Hz}$, giving 8 points for each temperature [Color figure can be viewed at wileyonlinelibrary.com]

given run. For a run at $400^{\circ} \mathrm{C}$, the collapse factor $e^{x}$ is just 1. The activation energy $E_{\mathrm{a}}$ is taken from Table 1 and is determined by a procedure explained below. To avoid cluttering the plots, we only present data at $100^{\circ}$ intervals, and only show data points for frequencies at integral powers of 10 .

We first discuss the plot for the $0.2 \% \mathrm{Mn}$ sample $\mathrm{S} 3$, because it is a "textbook example" of how collapsing the data improves its presentation. Only the results for $400^{\circ} \mathrm{C}$, $500^{\circ} \mathrm{C}$, and $600^{\circ} \mathrm{C}$ are shown, corresponding to the range of exponential temperature dependence resulting from electronic conductivity. The tendency for points for a given frequency to move leftward on an arc as temperature decreases is illustrated by the two points at the top of the arc, where for $400^{\circ} \mathrm{C}$ the top of the arc is at $100 \mathrm{~Hz}$, whereas at $500^{\circ} \mathrm{C}$ the top of the arc is at $10 \mathrm{kHz}$. These arc plots often appear as slightly distorted and depressed circular arcs, or sometimes as more than one arc. In the plot for $0.2 \% \mathrm{Mn}$ there is one arc, depressed to the extent that its center is at $(49500,-6500)$ ohm-m instead of (49 500, 0) ohm-m. To fit a depressed semicircle to the arc, one can use the following relation:

$$
\begin{aligned}
-\rho^{\prime \prime}= & {\left[\left(\rho_{\mathrm{dc}}{ }^{2} / 8 \rho_{\mathrm{pk}}-\rho_{\mathrm{pk}} / 2\right)^{2}+\left(\rho_{\mathrm{dc}}-\rho^{\prime}\right) \rho^{\prime}\right]^{1 / 2} } \\
& +\rho_{\mathrm{pk}} / 2-\rho_{\mathrm{dc}}{ }^{2} / 8 \rho_{\mathrm{pk}} .
\end{aligned}
$$

Here, $\rho_{\mathrm{pk}}$ is the peak value of $-\rho^{\prime \prime}$ for a given $T$. We note the corresponding $\rho_{\mathrm{pk}}^{\prime}$ value and assume a symmetric main arc, so that $\rho_{\mathrm{dc}}=2 \rho_{\mathrm{pk}}^{\prime}$.

The $0 \% \mathrm{Mn}$ arcs are depressed more than the $0.2 \% \mathrm{Mn}$ arcs. Also, the shape deviates from that for only one depressed arc, and consists of considerably depressed arcs at the left merging with the beginnings of second arcs on the right. The widest temperature range, from $100^{\circ} \mathrm{C}$ to $600^{\circ} \mathrm{C}$, could be used for the $1 \% \mathrm{Mn}$ sample arcs. At $100^{\circ} \mathrm{C}$ there is only a single arc. At $200^{\circ} \mathrm{C}$ there are two arcs of similar size. At $300^{\circ} \mathrm{C}$ there is one very asymmetric arc, while at higher temperatures there are large arcs at high frequency and small and flat arcs at low frequency. For 2\% Mn there are two different activation energies used in the $e^{x}$ collapse factors. For $200^{\circ} \mathrm{C}$ and $300^{\circ} \mathrm{C}$ the lower activation energy corresponding to ionic conductivity is used, and there are large arcs merging into the beginnings of smaller arcs. For $500^{\circ} \mathrm{C}$ and $600^{\circ} \mathrm{C}$ the higher activation 
energy corresponding to electronic conductivity is used. There is a large arc at $500^{\circ} \mathrm{C}$ but only the tail end of a large arc at $600^{\circ} \mathrm{C}$, both merging into low flat arcs. Appearance of a second arc in ceramics is generally attributed to grain boundary effects. In equivalent circuits, there is a grain boundary resistor in parallel with a grain boundary capacitor. This parallel pair is in series with a bulk resistor, and this three-element circuit is in parallel with a geometric capacitor. In a single crystal, the grain boundary resistor and capacitor would be absent. In a relaxor ferroelectric, the different dielectric responses of local polar regions can be expected to contribute additional arc flattening beyond the effects of grains and grain boundaries.

\section{3 $\mid$ DC resistivity}

The values chosen for $\mathrm{dc}$ resistivity $\rho_{\mathrm{dc}}$ are based on where each main high-frequency $-\rho^{\prime \prime}$ vs $\rho^{\prime}$ arc, such as those shown in Figures 3 and 4, extrapolates to the horizontal $\rho^{\prime}$ axis. If the arc has the shape of a flattened circular arc (circular but less than $180^{\circ}$ of arc), then we use the procedure associated with Equation 7 to find our assumed $\rho_{\mathrm{dc}}$. If the shape of the arc is clearly not circular, but instead shows a point of inflection in going to a second arc, we extrapolate the curvature of the initial arc until it meets the $\rho^{\prime}$ axis.

A graph showing $\rho_{\mathrm{dc}}$ points plotted as $\log \rho_{\mathrm{dc}}$ vs $10^{3} / T$ appears in Figure 5. The points for a given sample are generally fit by a straight line. For the $2 \% \mathrm{Mn}$ sample S3, the fit is to two straight lines, corresponding to what we believe is an ionic conduction mechanism at lower temperatures and an electronic conduction mechanism at higher temperatures. To complement the Figure 5 graph, Table 2 presents resistivities and their activation energies and their error bars. One might think that because for thermally activated conductivity with a single activation energy the resistivity obeys

$$
\rho=\rho_{0} \exp \left(E_{\mathrm{a}} / k T\right),
$$

one need only find and present error bars for $\rho_{0}$ and $E_{\mathrm{a}}$. One would do this by taking the log,

$$
\log \rho=\log \rho_{0}+\left(E_{\mathrm{a}} / K T\right)=\log (e) \log \rho_{0}+0.4343 E_{\mathrm{a}} / k T,
$$

and doing a least-squares fit to a straight line for the $\log \rho$ vs $1 / T$ points using $\log \rho$ and $E_{\mathrm{a}} / k$ as fit parameters. This is an inefficient and misleading procedure for two reasons. First, these two fitting parameters are highly correlated. Second, the error bars on $\log \rho_{0}$ will be much larger than the correct error bars on the data points because of the large extrapolation from the data points to the $1 / T=0$ point corresponding to $\rho_{0}$. Instead, we pick a reference temperature near the middle of the data range, at Kelvin

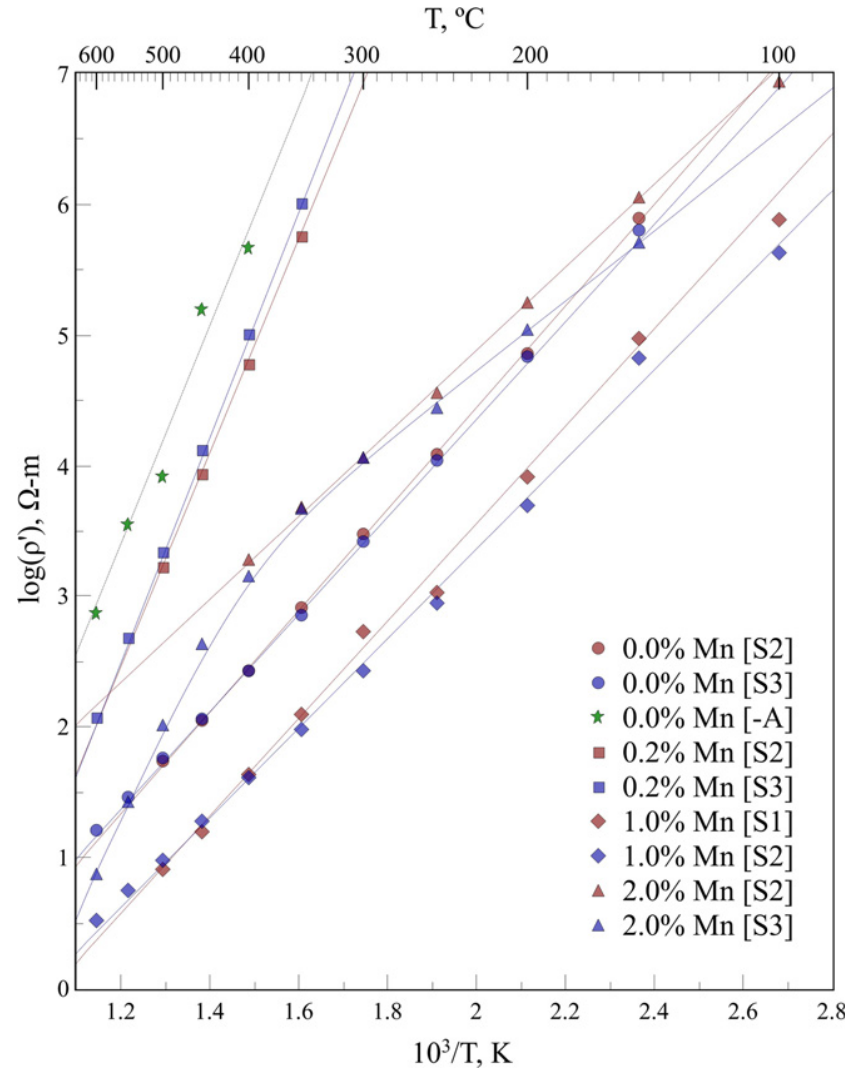

FIGURE 5 Semilogarithmic plot of dc resistivity vs inverse temperature. The dc resistivity values were determined by the procedure described in Section 3.3. The steeper and less steep lines or line segments are attributed, respectively, to electronic and ionic conductivities [Color figure can be viewed at wileyonlinelibrary.com]

temperature $T_{\mathrm{r}}$, and use the corresponding $\log \rho_{\mathrm{r}}$ as the fitting parameter, which will have only a weak correlation with the other fitting parameter, $E_{\mathrm{a}} / k$. Then the fit equation changes from Equation 8 to

$$
\log \rho=\log \rho_{r}+0.4343\left(E_{\mathrm{a}} / k\right)\left(1 / T-1 / T_{r}\right) .
$$

Then we find the $\left(\log \rho_{\mathrm{r}}, E_{\mathrm{a}} / k\right)$ pair giving the least rms error $\sigma$ for the $n$ data points, using

$$
\sigma=\left[\sum_{i=1}^{n}\left(\rho_{\text {i meas }}-\rho_{\text {i calc }}\right)^{2} /(n-1)\right]^{1 / 2} .
$$

From Equation 10 this $\sigma$ will be the rms error for the $T_{\mathrm{r}}$ temperature point, because the second term on the right vanishes and so it is assumed that the error for $E_{\mathrm{a}} / k$ does not enter.

To find the error bar for $E_{\mathrm{a}} / k$, we assume that by adding this error to the best fitting $E_{\mathrm{a}} / k$ value, but keeping the best fitting value for $\rho_{\mathrm{r}}$, we get the same increase in $\sigma$ using Equation 4 as we get using the best fitting value for $E_{\mathrm{a}} / k$ but increasing the $\rho_{\mathrm{r}}$ value by the best-fit $\sigma$ value. Once both of these error bars are found, we can use Equation 10 with $1 / T$ set to 0 to find $\rho_{0}$. By using the error bars for 
TABLE 2 Resistivity properties as functions of temperature

\begin{tabular}{lllllcl}
\hline Sample & $\boldsymbol{T}$ range & Fit range & $\boldsymbol{T}_{\mathbf{r}}$ & $\boldsymbol{E}_{\mathbf{a}}(\mathbf{e V})$ & $\boldsymbol{\rho}_{\mathbf{r}}(\mathbf{o h m}-\mathbf{m})$ & $\boldsymbol{\rho}_{\mathbf{0}}(\mathbf{o h m}-\mathbf{m})$ \\
\hline 0\% Mn S2 & $100-500$ & $150-500$ & 300 & $0.77 \pm 0.02$ & $2.9 \pm 0.2 \times 10^{3}$ & $4.8 \pm 1.6 \times 10^{-4}$ \\
\hline 0\% Mn S3 & $100-600$ & $150-600$ & 350 & $0.74 \pm 0.01$ & $8.1 \pm 0.6 \times 10^{2}$ & $7.8 \pm 1.8 \times 10^{-4}$ \\
\hline 0\% Mn, "A" & $25-600$ & $400-600$ & 500 & $1.66 \pm 0.30$ & $1.7 \pm 0.7 \times 10^{4}$ & $2.3 \times 10^{-7 \mathrm{a}}$ \\
\hline $0.2 \%$ Mn S2 & $100-500$ & $350-500$ & 400 & $1.62 \pm 0.01$ & $6.0 \pm 0.1 \times 10^{4}$ & $4.7 \pm 0.8 \times 10^{-8}$ \\
\hline $0.2 \%$ Mn S3 & $100-600$ & $350-600$ & 450 & $1.71 \pm 0.01$ & $1.26 \pm 0.03 \times 10^{4}$ & $1.4 \pm 0.2 \times 10^{-8}$ \\
\hline $1 \%$ Mn S1 & $100-500$ & $100-500$ & 250 & $0.74 \pm 0.07$ & $1.4 \pm 0.6 \times 10^{3}$ & $1.3 \times 10^{-4 b}$ \\
\hline $1 \%$ Mn S2 & $100-600$ & $100-600$ & 300 & $0.68 \pm 0.03$ & $3.2 \pm 0.8 \times 10^{2}$ & $3.2 \pm 2.1 \times 10^{-4}$ \\
\hline $2 \%$ Mn S2 & $100-500$ & $100-400$ & 200 & $0.63 \pm 0.02$ & $1.87 \pm 0.16 \times 10^{5}$ & $3.4 \pm 2.4 \times 10^{-2}$ \\
\hline $2 \%$ Mn S3 & $100-600$ & $150-350$ & 250 & $0.53 \pm 0.03$ & $3.1 \pm 0.2 \times 10^{4}$ & $2.4 \pm 0.1 \times 10^{-1}$ \\
\hline $2 \%$ Mn S3 & $100-600$ & $450-600$ & 500 & $1.46 \pm 0.06$ & $1.00 \pm 0.05 \times 10^{2}$ & $3.0 \times 10^{-8 c}$ \\
\hline
\end{tabular}

For sample "A" the dielectric data presented in Ref. [2] were converted to resistivity as described in Section 3.3. Fit $T$ range is for $\log \rho$ points that fall nearly on a straight line vs $10^{3} / T$. Here, $T_{\mathrm{r}}$ is the reference temperature near the midpoint of the measurement range whose corresponding $\rho_{\mathrm{r}}$ is a fit parameter. Both + and error bars are shown for $\rho_{0}$ values if they are significantly different because of the long extrapolation to zero reciprocal temperature of the exponential resistivity function. $E_{\mathrm{a}}$ values below and above $1 \mathrm{eV}$ are assumed to correspond, respectively, to ionic and electronic conductions.

${ }^{\mathrm{a}}$ Error limits are $5 \times 10^{-9}$ to $1 \times 10^{-5}$ ohm-m for this $\rho_{0}$ value.

${ }^{\mathrm{b}}$ Error limits are $2 \times 10^{-5}$ to $6 \times 10^{-4} \mathrm{ohm}-\mathrm{m}$ for this $\rho_{0}$ value.

${ }^{\mathrm{c}}$ Error limits are $1.8 \times 10^{-8}$ to $7.4 \times 10^{-8} \mathrm{ohm}-\mathrm{m}$ for this $\rho_{0}$ value.

$E_{\mathrm{a}} / k$ and $\rho_{\mathrm{r}}$, we can find the error bar for $\rho_{0}$, but the error bar for $E_{\mathrm{a}} / k$ will have by far the larger effect on finding the $\rho_{0}$ error.

In order of increasing Mn concentration, the following results in Figure 5 and Table 2 are discussed. For $0 \%$ $\mathrm{Mn}$, the first sample (S1) gave anomalous results, but the sample S2 and S3 results agree well with each other. For sample "A" from Ref. [2], the resistivities, as converted from their dielectric data plot using Equation A12 in the Appendix A, lay much higher than for samples S2 and S3. The pre-exponential $\rho_{0}$ was much lower, $2.3 \times 10^{-7} \mathrm{ohm}-\mathrm{m}$, close to the values for various metals and electronic semiconductors. The activation energy was much higher, $1.66 \mathrm{eV}$, again indicating electronic conductivity, dominating over the temperature range $400^{\circ} \mathrm{C}$ to $600^{\circ} \mathrm{C}$

Indications of two activation energies were found for the $0.2 \% \mathrm{Mn}$ samples. The first sample was run only up to $500^{\circ} \mathrm{C}$, but for samples S2 and S3 we went to $600^{\circ} \mathrm{C}$ and got results in good agreement, showing high activation energy indicative of electronic conductivity at higher temperatures. At lower temperatures there was a tendency toward lower activation energy, but no straight-line segments from which $E_{\mathrm{a}}$ could be found.

We ran two $1 \% \mathrm{Mn}$ samples, $\mathrm{S} 1$ up to $500^{\circ} \mathrm{C}$ and $\mathrm{S} 2$ to $600^{\circ} \mathrm{C}$, and obtained excellent agreement. They had low activation energy characteristic of ionic conductivity. Their resistivity was the lowest of all the samples, low enough that on Figure 5 the data points (as also found for $0 \% \mathrm{Mn}$ samples S2 and S3) did not reach the region where one would expect curvature to a higher slope indicating crossover to electronic conductivity.
For the first two $2 \%$ Mn samples, both run up to $500^{\circ} \mathrm{C}$, there was disagreement in that the second sample S2 showed lower resistivity. Both showed low activation energies consistent with ionic conductivity, and a steepening of the slope at high temperature indicating the beginning of a crossover to electronic conductivity. To clarify this situation, we ran a third sample S3, up to $600^{\circ} \mathrm{C}$. Up to $500^{\circ} \mathrm{C}$ the results from samples $\mathrm{S} 2$ and $\mathrm{S} 3$ agreed well, and by going to $600^{\circ} \mathrm{C}$ we obtained three data points for sample S3 falling on a steep straight line in Figure 5. This is the only sample for which we obtained two straight-line segments in Figure 5, indicating a low temperature region where ionic conductivity dominates and a high temperature region where electronic conductivity dominates.

\section{4 | SUMMARY}

Impedance spectroscopy measurements were made on $\left(\mathrm{Bi}_{1 / 2} \mathrm{Na}_{1 / 2}\right)_{0.925} \mathrm{Ba}_{0.075}\left(\mathrm{Ti}_{1-x} \mathrm{Mn}_{x}\right) \mathrm{O}_{3}$ ceramics $(x=0 \%$, $0.2 \%, 1.0 \%$, and $2.0 \%$ ). The results are presented on ColeCole plots of arcs of imaginary vs real resistivity. The resistivities are multiplied by "collapse factors" which remove the exponential temperature dependence. Extrapolation to zero frequency of the primary (high frequency) arc provides assumed dc resistivities. From logarithmic plots of $\mathrm{dc}$ resistivities vs inverse temperature we determine the activation energies for the conductivity. These fall into two groups, above $1 \mathrm{eV}$ attributed to electronic conductivity, and below $1 \mathrm{eV}$ attributed to ionic conductivity.

Various effects can cause variations in results from different samples. These include possible differences in 
preparation technique, and differences in electrical history (poling or piezoelectric measurements which require large applies voltage) which can affect phase coexistence and domain texturing, ${ }^{1,16,17}$ as well as effects of Mn valence. ${ }^{14}$ Correlations among results include increasing power law exponent $\gamma$ and increasing permittivity peak width parameter $\Delta$ with increasing Mn content, both for our present and previous $^{21}$ results.

We found previously ${ }^{21}$ that $0.2 \% \mathrm{Mn}$ doping gives the highest depolarization temperature $T_{\mathrm{d}}$ of $152^{\circ} \mathrm{C}$, which is important for piezoelectric applications, compared to only $93^{\circ} \mathrm{C}$ for $0 \% \mathrm{Mn}$. The piezoelectric coefficient $d_{33}$ of $170 \mathrm{pC} /$ $\mathrm{N}$ for $0.2 \% \mathrm{Mn}$ is only slightly lower than the $186 \mathrm{pC} / \mathrm{N}$ value for $0 \% \mathrm{Mn}^{21}$ Because this $0.2 \% \mathrm{Mn}$ doping seems best for applications, we mention here how the $0.2 \% \mathrm{Mn}$ results of our present study differ from those for the other compositions. The $0.2 \%$ Mn samples show considerably lower ionic conductivities, which will reduce heating for high voltage piezoelectric applications. They also have the highest Curie-Weiss temperature and Burns temperature. These results add to the knowledge base concerning lead-free piezoelectric ceramics, and how doping can improve performance and enhance thermal stability to allow operation of piezoelectric devices at higher temperatures and at higher power levels.

\section{ACKNOWLEDGMENTS}

Brandon Thiesen assisted with data acquisition, and Josh Sinrud and Kyle Allemeier resolved some IS program difficulties. The Montana State University Undergraduate Scholars Program provided financial support for Noah Archer. Helpful discussions concerning the FEM and XRD measurements were provided by Yves Idzerda, Recep Avci, and by Laura Kellerman who made these measurements.

\section{ORCID}

V. Hugo Schmidt (iD http://orcid.org/0000-0002-5346-4146

\section{REFERENCES}

1. Shvartsman VV, Lupascu DC. Lead-free relaxor ferroelectrics. $J$ Am Ceram Soc. 2012;95:1-26.

2. Anthoniappen J, Tu CS, Chen PY, et al. Structural phase stability and electric field induced relaxor-ferroelectric phase transition in $(1-x)\left(\mathrm{Bi}_{0.5} \mathrm{Na}_{0.5}\right) \mathrm{TiO}_{3}-x \mathrm{BaTiO}_{3}$ ceramics. $J$ Alloys Compd. 2015;618:120-126.

3. Zhang ST, Kounga AB, Aulbach E, Deng Y. Temperature-dependent electrical properties of $0.94 \mathrm{Bi}_{0.5} \mathrm{Na}_{0.5} \mathrm{TiO}_{3}-0.06 \quad \mathrm{BaTiO}_{3}$ ceramics. J Am Ceram Soc. 2008;91:3950-3954.

4. Chen PY, Chen CS, Tu CS, Cheng CD, Cherng JS. Relaxor effect on electric field induced large strain in $(1-x)\left(\mathrm{Bi}_{0.5} \mathrm{Na}_{0.5}\right) \mathrm{TiO}_{3}-x \mathrm{Ba}-$ $\mathrm{TiO}_{3}$ lead-free piezoceramics. Ceram Int. 2014;40:6137-6142.
5. Chen CS, Chen PY, Tu CS. Polar nanoregions and dielectric properties in high-strain lead-free $0.93\left(\mathrm{Bi}_{1 / 2} \mathrm{Na}_{1 / 2}\right) \mathrm{TiO}_{3}-$ $0.07 \mathrm{BaTiO}_{3}$ piezoelectric single crystals. $J$ Appl Phys. 2014;115:014105-014108.

6. Yoshii K, Hiruma Y, Nagata H, Takenaka T. Electrical properties and depolarization temperature of $\left(\mathrm{Bi}_{1 / 2} \mathrm{Na}_{1 / 2}\right) \mathrm{TiO}_{3}-\left(\mathrm{Bi}_{1 / 2} \mathrm{~K}_{1 / 2}\right)$ $\mathrm{TiO}_{3}$ lead-free piezoelectric ceramics. Jpn J Appl Phys. 2006;45:4493-4496.

7. Hiruma $\mathrm{Y}$, Nagata $\mathrm{H}$, Takenaka T. Phase diagrams and electrical properties of $\left(\mathrm{Bi}_{1 / 2} \mathrm{Na}_{1 / 2}\right) \mathrm{TiO}_{3}$-based solid solutions. J Appl Phys. 2008;104:124106.

8. Nagata $\mathrm{H}$, Koizumi N, Takenaka $\mathrm{T}$. Lead-free piezoelectric ceramics of $\left(\mathrm{Bi}_{1 / 2} \mathrm{Na}_{1 / 2}\right) \mathrm{TiO}_{3}-\mathrm{BiFeO}_{3}$ system. Key Eng Mater. 1999;169-170:37-40.

9. Hiruma Y, Imai Y, Watanabe Y, Takenaka T. Large electrostrain near the phase transition temperature of $\left(\mathrm{Bi}_{0.5} \mathrm{Na}_{0.5}\right) \mathrm{TiO}_{3}-\mathrm{SrTiO}_{3}$ ferroelectric ceramics. Appl Phys Lett. 2008;92:262904.

10. Wang K, Hussain A, Jo W, Rödel J. Temperature-dependent properties of $\left(\mathrm{Bi}_{1 / 2} \mathrm{Na}_{1 / 2}\right) \mathrm{TiO}_{3}-\left(\mathrm{Bi}_{1 / 2} \mathrm{~K}_{1 / 2}\right) \mathrm{TiO}_{3}-\mathrm{SrTiO}_{3}$ lead-free piezoceramics. J Am Ceram Soc. 2012;95:2241-2247.

11. Zhang ST, Kounga AB, Aulbach E, Rödel J. Giant strain in leadfree piezoceramics $\mathrm{Bi}_{0.5} \mathrm{Na}_{0.5} \mathrm{TiO}_{3}-\mathrm{BaTiO}_{3}-\mathrm{K}_{0.5} \mathrm{Na}_{0.5} \mathrm{NbO}_{3}$ system. Appl Phys Lett. 2007;91:112906.

12. Chen PY, Chen CS, Tu CS, Chang TL. Large E-field induced strain and polar evolution in lead-free $\mathrm{Zr}$-doped $92.5 \%\left(\mathrm{Bi}_{0.5} \mathrm{Na}_{0.5}\right)$ $\mathrm{TiO}_{3}-7.5 \% \mathrm{BaTiO}_{3}$ ceramics. J Eur Ceram Soc. 2014;34:42234233.

13. Wang SF, Tu CS, Chang TL, et al. Structural stability and depolarization of manganese-doped $\left(\mathrm{Bi}_{0.5} \mathrm{Na}_{0.5}\right)_{1-\mathrm{x}} \mathrm{Ba}_{\mathrm{x}} \mathrm{TiO}_{3}$ relaxor ferroelectrics. J Appl Phys. 2014;116:154101-154109.

14. Anthoniappen J, Tu CS, Chen PY, Chen CS, Idzerda YU, Chiu SJ. Raman spectra and structural stability in B-Site manganese doped $\left(\mathrm{Bi}_{0.5} \mathrm{Na}_{0.5}\right)_{0.925} \mathrm{Ba}_{0.075} \mathrm{TiO}_{3}$ relaxor ferroelectric ceramics. J Eur Ceram Soc. 2015;35:3495-3506.

15. Takenaka T, Maruyama K, Sakata K. $\left(\mathrm{Bi}_{1 / 2} \mathrm{Na}_{1 / 2}\right) \mathrm{TiO}_{3}-\mathrm{BaTiO}_{3}$ system for lead-free piezoelectric ceramics. Jpn J Appl Phys. 1991;30:2236-2239.

16. Jo W, Daniels JE, Jones JL, et al. Evolving morphotropic phase boundary in lead-free $\left(\mathrm{Bi}_{1 / 2} \mathrm{Na}_{1 / 2}\right) \mathrm{TiO}_{3}-\mathrm{BaTiO}_{3}$ piezoceramics. $J$ Appl Phys. 2011;109:014110-014117.

17. Anthoniappen $\mathrm{J}$, Lin $\mathrm{CH}$, Tu CS, et al. Enhanced piezoelectric and dielectric responses in $92.5 \%\left(\mathrm{Bi}_{0.5} \mathrm{Na}_{0.5}\right) \mathrm{TiO}_{3}-7.5 \% \mathrm{BaTiO}_{3}$ ceramics. J Am Ceram Soc. 2014;97:1890-1894.

18. Bokov AA, Ye ZG. Recent progress in relaxor ferroelectrics with perovskite structure. J Mater Sci. 2006;41:31-52.

19. Wang FF, Xu M, Tang YX, Wang T, Shi WZ, Ma C. Large strain response in the ternary $\mathrm{Bi}_{0.5} \mathrm{Na}_{0.5} \mathrm{TiO}_{3}-\mathrm{BaTiO}_{3}-\mathrm{SrTiO}_{3}$ solid solutions. J Am Ceram Soc. 2012;95:1955-1959.

20. Rödel J, Jo W, Seifert KTP, Anton EM, Granzow T. Perspective on the development of lead-free piezoceramics. J Am Ceram Soc. 2009;92:1153-1177.

21. Anthoniappen J, Tu CS, Chen CS, Chen PY, Idzerda YU. Dielectric, ferroelectric, and depolarization properties of B-Site manganese-doped $\quad 0.925\left(\mathrm{Bi}_{0.5} \mathrm{Na}_{0.5}\right) \mathrm{TiO}_{3}-0.075 \mathrm{BaTiO}_{3} \quad$ solid solutions. Ceram Int. 2016;42:8402-8408.

22. Schmidt VH, Tuthill GF, Tu CS, Schogoleva TV, Meschia SC. Conductivity across random barrier distribution as origin of large low-frequency dielectric peak in perovskite crystals and ceramics. J Phys Chem Solids. 1996;57:1493-1497. 
23. Zhu M, Liu L, Hou Y, Wang H, Yan H. Microstructure and electrical properties of $\mathrm{MnO}$-doped $\left(\mathrm{Na}_{0.5} \mathrm{Bi}_{0.5}\right)_{0.92} \mathrm{Ba}_{0.08} \mathrm{TiO}_{3}$ leadfree piezoceramics. J Am Ceram Soc. 2007;90:120-124.

24. Martirena HT, Burfoot JC. Grain-size and pressure effects on the dielectric and piezoelectric properties of hot-pressed PZT-5. Ferroelectrics. 1974;7:151-152.

25. Macdonald JR, Johnson WB. In: Barsoukov E, Macdonald JR, eds. Impedance Spectroscopy, 2nd edn. Hoboken: Wiley; 2005:7.

26. Tu CS, Yang WC, Schmidt VH, Chien RR. Origins of dielectric response and conductivity in $\left(\mathrm{Bi}_{1-x} \mathrm{Nd}_{x}\right) \mathrm{FeO}_{3}$ multiferroic ceramics. J Appl Phys. 2011;110:114114.

27. Raju GG. Dielectrics in Electric Fields, 2nd edn. Boca Raton: CRC Press; 2017:348.

\section{SUPPORTING INFORMATION}

Additional Supporting Information may be found online in the supporting information tab for this article.

How to cite this article: Schmidt VH, Archer N, Tu C-S. Impedance spectroscopy of bismuth sodium titanate: Barium titanate ceramics with manganese doping. J Am Ceram Soc. 2018;101:713-722. $\underline{\text { https://doi.org/10.1111/jace.15236 }}$

\section{APPENDIX A}

\section{RELATION BETWEEN IMPEDANCE} $\rho=\rho^{\prime}+\mathbf{j} \rho "$ AND PERMITTIVITY $\varepsilon=\varepsilon^{\prime}+\mathbf{j} \varepsilon "$

The apparatus supplies an ac voltage $V$ to a sample that is a uniform slab of thickness $d$ and area $A$, so that the electric field is $V / d=E=E_{0} \exp (\mathrm{j} \omega t)$. Then the current density $J$ can be described in terms of complex conductivity $\sigma$ as

$$
J=\sigma E=\left(\sigma^{\prime}+j \sigma^{\prime \prime}\right) E .
$$

We describe the response in terms of complex resistivity $\rho=1 / \sigma$, so

$$
\sigma=1 / \rho=1 /\left(\rho^{\prime}+j \rho^{\prime \prime}\right)=\left(\rho^{\prime}-j \rho^{\prime \prime}\right) /\left(\rho^{\prime 2}+\rho^{\prime \prime 2}\right) .
$$

Then the response in Equation A1 can be written as

$$
J=\left[\left(\rho^{\prime}-j \rho^{\prime \prime}\right) /\left(\rho^{\prime 2}+\rho^{\prime \prime 2}\right)\right] E .
$$

The current density $J$ can also be described as the time derivative of the electric displacement $D$, where

$$
D \equiv \varepsilon_{0} E+P .
$$

For a linear dielectric this can be written

$$
D=\varepsilon_{0} \varepsilon E=\varepsilon_{0}\left(\varepsilon^{\prime}+j \varepsilon^{\prime \prime}\right) E .
$$

To find the corresponding $J$, we take the time derivative of Equation A5 and obtain

$$
J=j \omega \varepsilon_{0}\left(\varepsilon^{\prime}+j \varepsilon^{\prime \prime}\right) E=\omega \varepsilon_{0}\left(-\varepsilon^{\prime \prime}+j \varepsilon^{\prime}\right) E .
$$

The $-\omega \varepsilon_{0} \varepsilon^{\prime \prime} E$ term is the conduction current density. The $j \omega \varepsilon_{0} \cdot \varepsilon^{\prime} E$ term is the capacitive charging current density which leads the field by $90^{\circ}$. Equating the real parts of Equations $\mathrm{A} 3$ and $\mathrm{A} 6$, we get

$$
\varepsilon^{\prime \prime}=-\rho^{\prime} / \omega \varepsilon_{0}\left(\rho^{\prime 2}+\rho^{\prime \prime 2}\right) .
$$

Sometimes the lossy part of the permittivity is reported in terms of $\tan \delta$ rather than $\varepsilon^{\prime \prime}$. Then to have $\tan \delta$ be positive, the definition $\tan \delta=-\varepsilon^{\prime \prime} / \varepsilon^{\prime}$ must have the minus sign. Equation A6 then becomes

$$
J=\omega \varepsilon_{0} \varepsilon^{\prime}(\tan \delta+j) E .
$$

We find the relations between resistivity and permittivity by equating separately the real and imaginary $J$ terms in Equations A3 and A8. From the imaginary terms we get

$$
\varepsilon^{\prime}=-\rho / \omega \varepsilon_{0}\left(\rho^{\prime 2}+\rho^{\prime \prime 2}\right) .
$$

Then we plug $\varepsilon^{\prime}$ from Equation A9 into Equation A8 and solve for $\tan \delta$ by equating the real parts of Equation $\mathrm{A} 3$ and transformed Equation A8, and obtain

$$
\tan \delta=-\rho^{\prime} / \rho^{\prime \prime} .
$$

To obtain the inverse relations, we start by noting that from Equation A10, $\rho^{\prime}=-\rho^{\prime \prime} \tan \delta$. Then we insert this relation for $\rho^{\prime}$ into Equation A9 and solve for $\rho^{\prime \prime}$, to obtain

$$
\rho^{\prime \prime}=-1 / \omega \varepsilon_{0} \varepsilon^{\prime}\left(\tan ^{2} \delta+1\right) .
$$

Finally, we combine Equations A10 and A11 to solve for $\rho^{\prime}$, and obtain

$$
\rho^{\prime}=\tan \delta / \omega \varepsilon_{0} \varepsilon^{\prime}\left(\tan ^{2} \delta+1\right)
$$

Using Equations A9-A12, we can transform between the resistivity and permittivity representations, without assumptions about an equivalent circuit. Expressions related to Equations A9-A12 appear elsewhere ${ }^{25,27}$ but without the derivation, and in terms of $\varepsilon^{\prime \prime}$ instead of $\tan \delta$, and complex impedance $Z$ together with empty-cell capacitance instead of complex resistivity $\rho$. 